\title{
Surgical Management of Cervico-facial Cystic Lymphangioma in Children
}

\author{
O. Oulghoul, FZ. Hadid, O. Benhoummad, Y. Rochdi, A. Raji
}

\section{ABSTRACT}

Introduction: Cystic lymphangioma or cystic hygroma is a congenital malformation of the lymphatic system that manifests as a soft, benign, and painless mass. It originates from remnants of embryonic lymphatic tissue that retains the potential for proliferation.

Material and methods: Our retrospective study involved 16 cases of cystic lymphangioma managed between 2017 and 2020.

Results: This study included 9 girls and 7 boys with a mean age of 4.2 years. Cystic lymphangioma was visible in 7 cases at birth and in 6 cases before the age of 2 years, and beyond 2 years in 3 cases. The tumor was cervical in 11 cases, including one case of parotid extension, and 02 cases of sub maxillary extension, jugal in one and one case of parotid localization, and one case of lingual localization. Surgical indication was based on clinical examination and imaging in all cases. Excision was considered complete in 12 cases and incomplete in four cases. In three cases, excision was difficult due to adhesion to the internal jugular vein and the carotid bifurcation, base of the tongue in one case and facial nerve in one case. Early complications were, hematoma [one case], lymphorrhea [one case], jugal recurrence [one case] nine months after surgical excision.

Conclusion: Cervico-facial cystic lymphangioma is a particular pathology whose management is challenging, complex and multidisciplinary.

Keywords: Cystic hygroma, Cystic lymphangioma, Cystic mass in child, Neck surgery.

\section{INTRODUCTION}

Cystic lymphangioma or cystic hygroma is a relatively rare group of congenital dysplasia developed from lymphatic vessels, and was described since 1828 [1]-[3].

Classification of Landing and Father identifies three types [4]: capillary lymphangioma; cavernous lymphangioma poorly limited mass involving especially lips and tongue and finally the LK with macro- and or micro-cystic. A macro cystic lymphangioma contain one or more cavities large enough to be visualized on ultrasound (at least $1 \mathrm{~cm}$ in diameter) [5].

Cystic lymphangioma most often appears after birth or before the second year of life in 75\% of cases [6]. Many treatments have been proposed, primarily surgery [7]-[8]. It is a difficult surgery especially in the cervical region where the risk of nerve damage is elevated [5].

\section{Patients And Methods}

A retrospective study was conducted at the ENT-HNS department Mohamed VI Marrakech Morocco between
Submitted : April 29, 2021

Published : June 20, 2021

ISSN: $2593-8339$

DOI: $10.24018 /$ ejmed.2021.3.3.840

O. Oulghoul*

MD, ENT-HNS Department, Mohamed VI University Hospital Centre, Marrakech, Morocco.

(e-mail: oulghoul.omar@gmail.com) F. Hadid

MD, ENT-HNS Department, Mohamed VI University Hospital Centre, Marrakech, Morocco.

O. Benhoummad

MD, ENT-HNS Department, Mohamed

VI University Hospital Centre, Marrakech, Morocco.

Y. Rochdi

PR, ENT-HNS Department, Mohamed VI University Hospital Centre, Marrakech, Morocco.

A. Raji

PR, ENT-HNS Department, Mohamed VI University Hospital Centre, Marrakech, Morocco.

*Corresponding Author
January 2017 and December 2020. During this period, 16 children hospitalized for cystic lymphangioma were included. Analysis was performed using data from patients' clinical records. The following information was collected: age, sex, history, symptoms, physical examination data, location and size of the mass, radiological workup, surgical technique and post-therapeutic evolution. All patients had a complete clinical examination. The diagnosis of cystic lymphangioma was evoked on clinical examination in front of a soft cervical and/or facial swelling with or without compressive signs. Further radiological workups were ultrasound, CT, and for some MRI. The treatment was surgical in all cases followed by histological study of the specimen. Postoperative monitoring was clinical. Ultrasound was performed at the slightest doubt.

\section{RESUlts}

16 patients with cervicofacial cystic lymphangioma were included, 7 males and 9 females for a sex ratio of 1.28 in favor of females.

The mean age was 4.2 years, with extremes ranging from one week to 12 years old. In 5 cases the children were less 
than 12 months old, in 7 cases between 1 and 6 years, and in 4 cases more than 6 years. The cystic lymphangioma was discovered since birth in 7 cases, and before the age of 2 years in 6 cases, and beyond 2 years in 3 cases.

Various regions were involved: cervical location in 11 cases (Fig. 1) of which 06 cases were left and 05 cases right, left sub maxillary in two cases, and lingual in one case (Fig. 2), one case of right parotid location (Fig. 3) and one case of left jugal location. The size of the cystic lymphangioma, varied between 2.5 and $8.5 \mathrm{~cm}$ with an average of $5 \mathrm{~cm}$. In 9 patients, the mass was $2.5 \mathrm{~cm}$ to $5 \mathrm{~cm}$ in diameter; in 7 patients it was larger than $5 \mathrm{~cm}$.

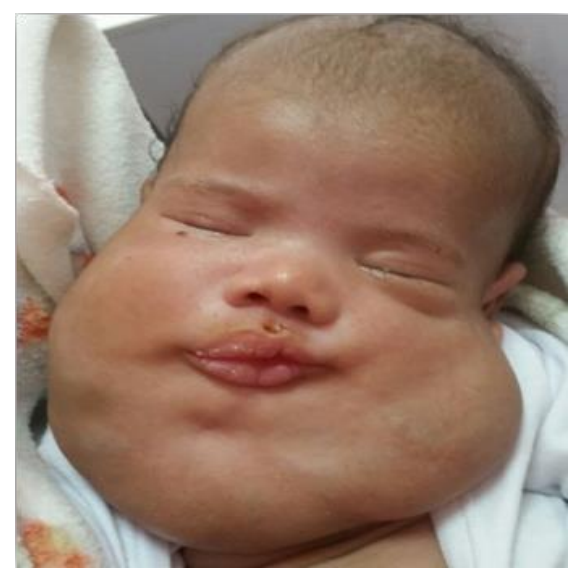

Fig. 1. Large cervical hygroma.

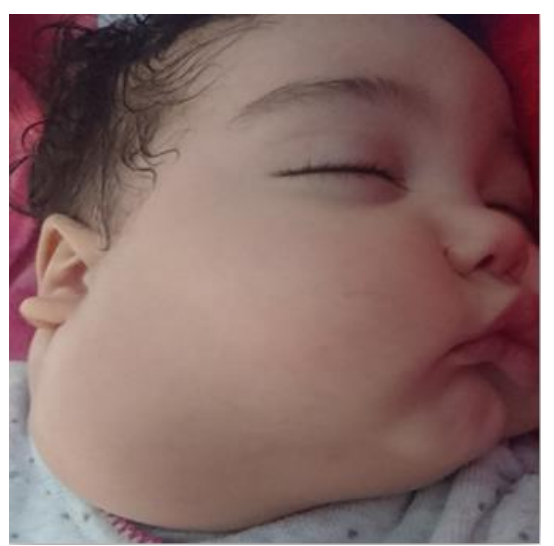

Fig. 2. Cystic hygroma of the parotid gland.

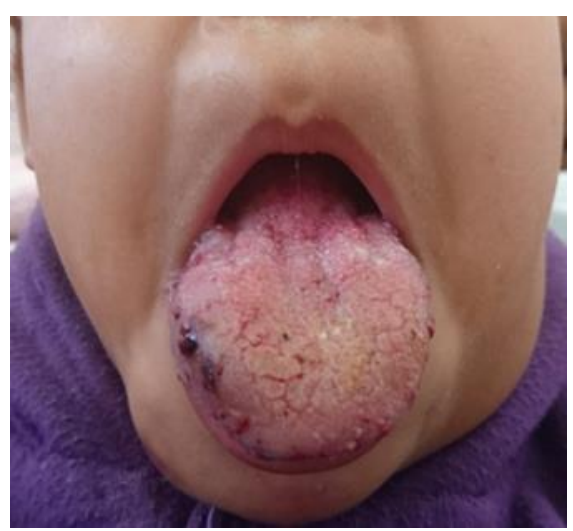

Fig. 3. Lingual hygroma

Pre-therapeutic work-up included a cervical ultrasound in eight cases (Fig. 4), a preoperative CT scan in two cases (Fig. 5) and MRI in 7 cases (Fig. 6).

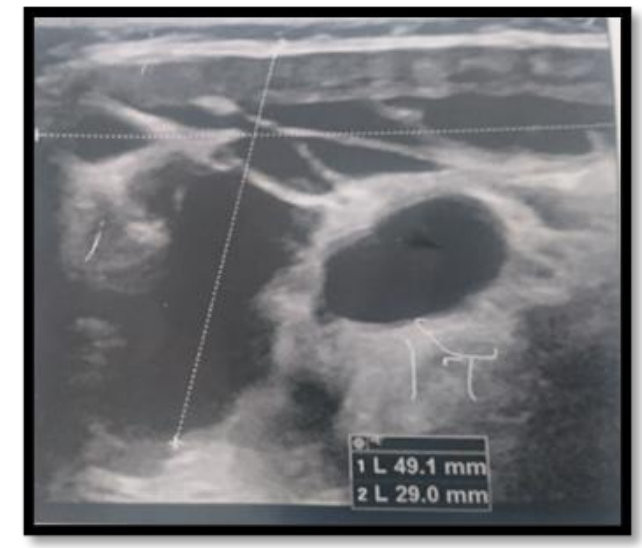

Fig. 4. Ultrasound image of cystic hygroma.

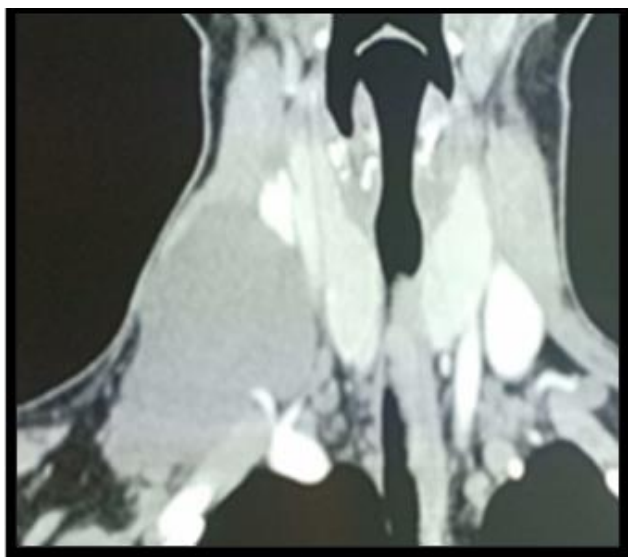

Fig. 5. CT scan of a right sus clavicular hygroma.

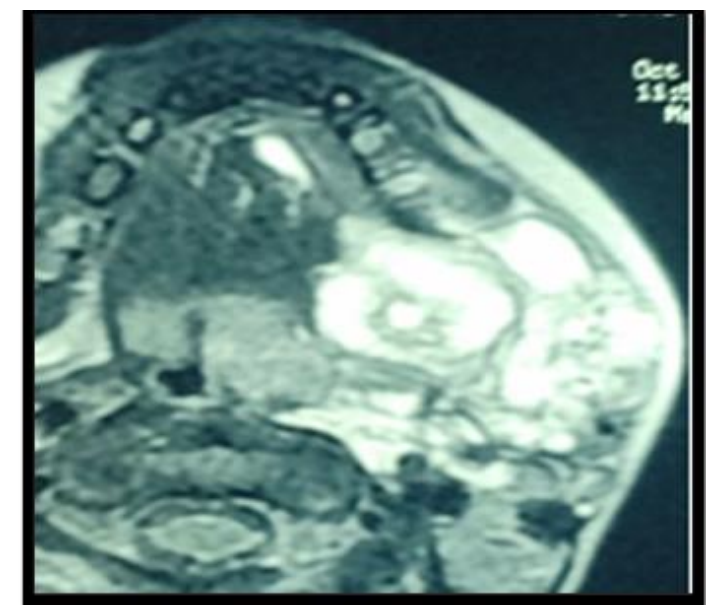

Fig. 6. MRI image of submaxillary hygroma.

Surgery was indicated in all cases due to dysphagia in 2 patients, dyspnea in 3 patients, failure of medical treatment in lingual localization. Deformity or dysmorphism alone, without functional impairment was the indication for surgery in 10 patients.

Resection was considered complete in 12 cases (Fig. 7), and incomplete in 04 cases: in two cases due to adhesion to the carotid bifurcation, in one case because of its adhesion to the base of the tongue and in one case due to its adhesion to the facial nerve. 


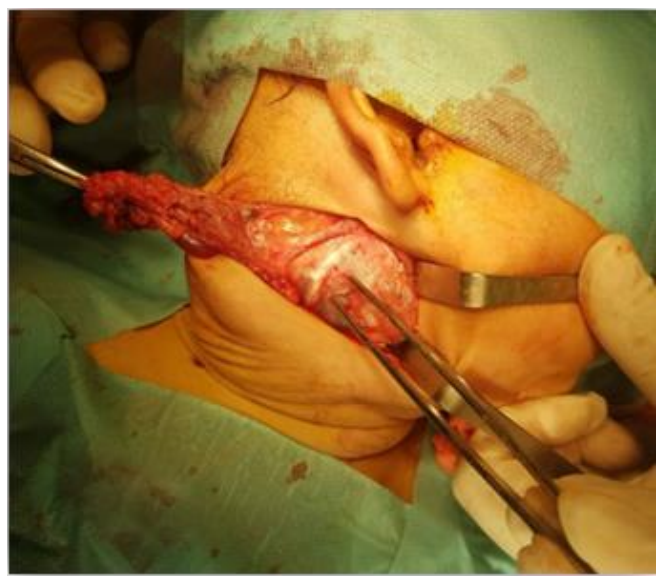

Fig. 7. Peroperative image of cervical hygroma.

Histological examination of the specimen revealed 11 cases of macroscopic lymphangioma, 03 cases of capillary lymphangioma and two cases of cavernous lymphangioma (Fig. 8).

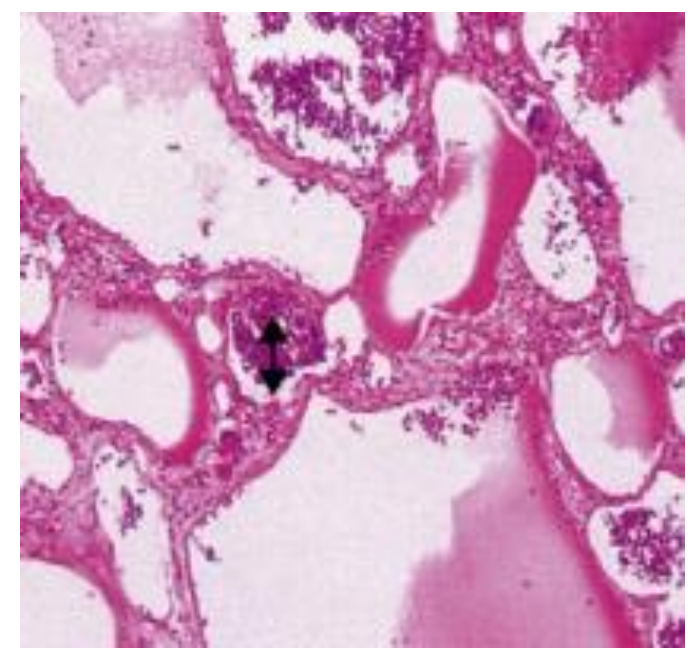

Fig. 8. Histological aspect of cystic hygroma.

Postoperative evolution was without complication in 13 cases. Lymphorrhea was noticed in one case (cervical lymphangioma with parotid extension) and was managed by compression dressings. There was also one case of hematoma (left jugal lymphangioma) drained with good evolution and one case of local infection and wound opening regarding the lingual localization. We had a case of recurrence of left jugal localization nine months after the intervention which benefited from a successful revision surgery later.

\section{DISCUSSION}

Lymphangioma is a rare congenital cervical malformation. It represents $5 \%$ of pediatric benign congenital masses, with cervicofacial locations in $75 \%$ [9].

We reported 16 cases of cystic cervicofacial lymphangioma in children over a period of 4 years, a rate of four cases per year. This rate is higher than what was reported in other series [4].

The most frequent location is in the posterior cervical triangle $(75-80 \%)$ due to the presence of the extensive lymphatic system. Clinical signs vary from a simple presence of a painless mass to signs of compression: dyspnea, dysphagia and difficulty feeding with regurgitation [9]-[10] to rarely symptoms of nerve invasion. Clinical appearance is a soft regular or poly-lobed mass.

The diagnosis of cystic lymphangioma is made on the basis of clinical and paraclinical data. Cervical ultrasonography specifies location, size, and number of cysts [5]. CT and MRI with contrast injection are useful in planning the surgery.

Non-surgical treatment of lymphangioma has been advocated by some authors to avoid risks of surgery and pending for spontaneous resolution [3]. Radiotherapy [RT] is now abandoned because of the risk of malignant transformation. Sclerotherapy with Bleomycin and OK-432 has been used successfully, especially in children and orbital location. Sclerosing agents are also used. The disadvantages of these agents are their unpredictable results and extensive sclerosis, which can make future surgery extremely difficult when it is necessary [11]-[12].

Surgery is considered the treatment of choice for cystic lymphangioma, especially for macro cystic forms. Age of surgery is debatable, some authors consider that it is necessary to wait until six to nine months for general anesthesia to be less risky, for others it must be early, often in a newborn or infant [13]-[15].

In our series, two cases were operated early due to respiratory distress. Surgical procedure must be as complete as possible to avoid recurrence. However, resection should not induce postoperative functional and aesthetic complication for a condition that remains benign. These risks are more frequent for parotid localizations. In our series, resection was incomplete in parotid location due to the adhesion of the cystic hygroma to facial nerve.

Complication rate of surgery in an expert hand is estimated to $12 \%$ to $33 \%$ [16]-[17], in our series complication rate is at $23 \%$. Most frequent complications are bleeding; wound infection as in our cases and nerve damage [18]-[19]. Recurrence rate in literature is variable between $15 \%$ to $55 \%$ [19]. We had one case of recurrence after complete surgical resection.

\section{CONCLUSION}

Cervicofacial cystic hygroma is a congenital malformation that appears in early age, easy to diagnose and confirmed by imaging. Surgery is the best solutions, despite its difficulties and risks, in some cases; it must be done in early age in case of life-threatening emergency. Total removal is the only way to minimize recurrence risk but should not be at the cost of nerve or any functional damage.

\section{REFERENCES}

[1] Sabin FR. In: The lymphatic system in human embryos with consideration of the morphology of the system as a whole. Philadelphie: J.P. Lipspincott company; 1912. p. 709-15.

[2] François M, Le Guillou C, De Pont J, Aboucaya JP, Contencin P, Narcy P. Les lymphangiomes cervicofaciaux chez l'enfant. Ann Otolaryngol 1986; 103:113-7.

[3] Kennedy TL, Whitaker M, Pelliteri P, Wood WE Cystichygroma/lymphangioma: a rational approach to management. Laryngoscope 2001; 111:1929-37.

[4] Ozen IO, Moralioglu S, Karabulut R, et al. Surgical treatment of cervicofacial cystic hygromas in children. ORL J Otorhinolaryngol Relat Spec 2005; 67:331-4.

[5] Anne F, Hurtier O, Garcia JF, Filppini JF, Piriou A. Cystic lymphangioma of the neck in adults. Contribution of ultrasonography and computer tomography. Apropos of a case. Ann Radiol [Paris] 1992 $35: 212-6$. 
[6] Tekou H, Maboodou A, Feteke L, Foly A, Senah KC, Atanley R. Les lymphangiomes kystiques du cou del'enfant à Lomé. Tunis Med 1998; 76:24-7.

[7] Ameh EA, Nmadu PT. Cervical cystic hygroma: pre-,intra-, and postoperative morbidity and mortality in Zaria, Nigeria. Pediatr Surg Int 2001; 17:342-3.

[8] Pia F, Aluffi P, Olina M. Cystic lymphangioma in the head and neck region. Acta Otorhinolaryngol Ital 1999; 19:87-90.

[9] Gugliantini P, Fabriello G, D'Onofrio M. Cystic hygromaof the neck. Exploration with iodimated contrast media. Ann Radiol [Paris]1975; 18:453-7.

[10] Bill AH, Summer DS. A unified concept of lymphangioma and cystic hygroma. Surg GynecolObstet1965; 120:79-86.

[11] Martinot, S Descamps, P Févier. Evaluation du traitement des lymphangiomes kystiquespar injection percutanée d'Ethibloc chez 20 patients Arch Pediatr 1997:4:8-14.

[12] Raji A, Essaadi M, Touhami M, Chekkoury IA, Benchakroun Y. Les lymphangiomes kystiques cervico faciauxde l'enfant. À propos de 15 cas. Maghreb Med 2000;20:133-6.
[13] Serryth Dominic Colbert *, Leonie Seager, Fahim Haider. Lymphatic malformations of the head and neck-current concepts in management British Journal of Oral and Maxillofacial Surgery 51 [2013] 98-102

[14] Fung K, Poenaru D, Soboleski DA, Kamal IM. Impact of magnetic resonance imaging on the surgical management of cystic hygromas. J Pediatr Surg 1998; 33:839-41.

[15] Grabb WC, Dingman RO, Oneal RM, Dempsey PD. Facial hamartoma in children: neurofibroma, lymphangioma and hemangioma. Plast Reconstr Surg 1980; 66:509-27.

[16] Mandel L. Parotid area lymphangioma in an adult: case report. J Oral Maxillofac Surg 2004; 62:1320-3

[17] Edwards PD, Rahbar R, Ferraro NF, Burrows PE, Mulliken JB Lymphatic malformation of the lingual base and oral floor. Plast Reconstr Surg 2005; 115:1906-15.

[18] McGill TJ, Forsen JW, Mulliken JB. Haemangioma and vascular anomalies of the head and neck. In: Cummings CW, Harker LA, Krause CJ, et al., editors. Otolaryngology: head and neck surgery. 3rd ed. St. Louis: Mosby; 1998. p. 66-80.

[19] Kennedy TL. Cystic hygroma-lymphangioma: a rare and still unclear entity. Laryngoscope 1989; 99:1-10. 